\title{
Further Developments on the T-Transmuted X Family of Distributions
}

\author{
Clement Boateng Ampadu ${ }^{1 *}$ and Girish Babu ${ }^{2}$ \\ 131 Carrolton Road, Boston, MA 02132-6303, USA \\ ${ }^{2}$ Department of Statistics, Government Arts and Science College, India \\ Submission: April 12, 2018; Published: July 09, 2018 \\ *Corresponding author: Clement Boateng Ampadu, 31 Carrolton Road, Boston, MA 02132-6303, USA; Email: drampadu@hotmail.com
}

Abstract

We review the T-Transmuted Family of Distributions introduced in [1] and propose some further developments of this class of distributions.

Keywords: $T-X(W)$ family of distributions; Transmuted family of distributions; Biological data; Health data; Quadratic rank; Transmutation map; Monotonic; Beta-generated; Random variable; Integral representation; Base distribution; Plethora; Probability distributions; Quantile function

\section{Introduction}

\section{Transmuted family of distributions}

According to the quadratic rank transmutation map (QRTM) approach in [2], the CDF of the transmuted family of distributions is given by

$$
F(x):=(1+\lambda) G(x)-\lambda G\left(x^{2}\right)
$$

Where $-1 \leq \lambda \leq 1$ and $G(x)_{\mathrm{c}}$ is the $\mathrm{CDF}$ of the base distribution. When $\lambda=0$ we get the

\section{CDF of the base distribution}

Remark 1.1. The PDF of the transmuted family of distributions is obtained by differentiating the CDF above.

A plethora of results discussing properties and applications of this class of distributions have appeared in the literature, and for examples see [3]

\section{$T-X(W)$ family of distributions}

This family of distributions is a generalization of the betagenerated family of distributions first proposed by Eugene et.al [4]. In particular, let $r(t)$ be the PDF of the random variable $T \in[a, b],-\infty \leq a<b \leq \infty$, and let $W(F(x))$ be a monotonic and absolutely continuous function of the CDF $F(x)$ of any random variable ${ }^{X}$. The CDF of a new family of distributions defined by Alzaatreh et.al [5] is given by

$$
G(x)=\int_{a}^{W(F(x))} r(t) d t=R\{W(F(x))\}
$$

Where $R(\cdot)$ is the CDF of the random variable $T$ and $a \geq 0$

Remark 1.2. The PDF of the $T-X(W)$ family of distributions is obtained by differentiating the CDF above

Remark 1.3. When we set $W(F(x)):=-\ln (1-F(x))$, then we use the term "T-X Family of Distributions" to describe all subclasses of the $T-X(W)$ family of distributions induced by the weight function $W(x)=-\ln (1-x)$. A description of different weight functions that are appropriate given the support of the random variable $T$ is discussed in [5]. A plethora of results studying properties and application of the $T-X(W)$ family of distributions have appeared in the literature, and the research papers, assuming open access, can be easily obtained on the web via common search engines, like Google, etc.

\section{T-Transmuted $\mathrm{X}$ family of distributions}

This class of distributions appeared in [1]. In particular the $\mathrm{CDF}$ admits the following integral representation for $a \geq 0$

$$
J(x)=\int_{a}^{-\ln (1-F(x))} r(t) d t
$$

Where $r(t)$ is the PDF of the random variable $T$ and $F(x)$ is the transmuted CDF of the random variable $X$, that is,

$$
F(x):=(1+\lambda) G(x)-\lambda G\left(x^{2}\right)
$$

Where $-1 \leq \lambda \leq 1$ and $G(x) c$ is the CDF of the base distribution.

Remark 1.4. The PDF of the T-Transmuted $X$ family of distributions is obtained by differentiating the CDF above. 


\section{Further developments}

In this section, inspired by quantile generated probability distributions [6], we propose some new extensions of the T-Transmuted $\mathrm{X}$ family of distributions. We give the CDF of these new class of distributions, only in integral form. However, the CDF and PDF can be obtained explicitly by applying Theorem 2.2 and Theorem 2.3, respectively [7].

\section{The $q_{T}-X$ family of distributions}

Definition 2.1. Let $V$ be any function such that the following holds:

I. $F(x) \in[V(a), V(b)]$

II. $\quad F(x)$ is differentiable and strictly increasing

III. $\lim _{x \rightarrow-\infty} F(x)=V(a)$ and $\lim _{x \rightarrow-\infty} F(x)=V(b)$

then the CDF of the $q_{T}-X$ family induced by $V$ is given by

$K(x)=\int_{a}^{V(F(x))} \frac{1}{r(Q(t))} d t$

Where $\frac{1}{r(Q(t))}$ is the quantile density function of random variable $T \in[a, b]$, for $-\infty \leq a<b \leq \infty$, and $F(x)$ is the CDF of any random variable $X$.

Theorem 2.2. The CDF of the $q_{T}-X$ c family induced by $V$ is given by

$$
K(x)=Q[V(K(x))]
$$

Proof. Follows from the previous definition and noting that $Q^{\prime}=\frac{1}{r^{o} Q}$

Theorem 2.3. The PDF of the $q_{T}-X$ family induced by $V$ is given by

$$
K(x)=\frac{f(x)}{r[Q(V(x))]} V^{\prime}[K(x)]
$$

Proof. $k=K^{\prime}, \quad Q^{\prime}=\frac{1}{r^{o} Q}, F^{\prime}=f$, and $K$ is given by Theorem 2.2

Remark 2.4. When the support of $T$ is $[a, \infty)$, where $a \geq 0$, we can take $V$ as follows
a. $\quad V(x)=1-e^{-x}$
b. $\quad V(x)=\frac{x}{1+x}$
c. $\quad V(x)=\left[1-e^{-x}\right]^{\frac{1}{\alpha}}$, where $\alpha>0$
d. $\quad V(x)=\left[\frac{x}{1+x}\right]^{\frac{1}{\alpha}}$, where $\alpha>0$

Remark 2.5. When the support of $T$ is $(-\infty, \infty)$, we can take $V$ as follows

$$
\begin{aligned}
& \text { a. } \quad V(x)=1-e^{-e^{x}} \\
& \text { b. } \quad V(x)=\frac{e^{x}}{1+e^{x}}
\end{aligned}
$$

$$
\begin{aligned}
& \text { c. } V(x)=\left[1-e^{e^{x^{x}}}\right]^{\frac{1}{\alpha}} \text {, where } \alpha>0 \\
& \text { d. } \quad V(x)=\left[\frac{e^{x}}{1-e^{e^{x}}}\right]^{\frac{1}{\alpha}}, \text { where } \alpha>0
\end{aligned}
$$

\section{Some $q_{T}$ transmuted $X$ family of distributions}

In what follows we assume the random variable $T$ has PDF $r(t)$ and quantile function $Q(t)$. We also assume the random variable $X$ has transmuted $\mathrm{CDF}$

$$
(1+\lambda) G(x)-\lambda G(x)^{2}
$$

Where $-1 \leq \lambda \leq 1$ and $G(x)$ is the CDF of the base distribution.

\section{Families of $q_{T}$ transmuted $X$ distributions of Type I}

The CDF has the following integral representation for $\alpha>0$ and $\alpha \geq 0$

$$
K(x)=\int_{a}^{\left[1-e^{-\left\{(+\lambda) G(x)-\lambda G(x)^{2}\right\}}\right]^{\frac{1}{\alpha}}} \frac{1}{r(Q(t))} d t
$$

\section{Families of $q_{T}$ transmuted $X$ distributions of Type II}

The CDF has the following integral representation for $\alpha>0$ and $\alpha \geq 0$

$$
K(x)=\int_{a}^{\left[\frac{\left\{(1+\lambda) G(x)-\lambda G(x)^{2}\right\}}{1+\left\{(1+\lambda) G(x)-\lambda G(x)^{2}\right\}}\right]^{\frac{1}{\alpha}}} \frac{1}{r(Q(t))} d t
$$

\section{Families of $q_{T}$ transmuted $X$ distributions of Type III}

The CDF has the following integral representation for $\alpha>0$

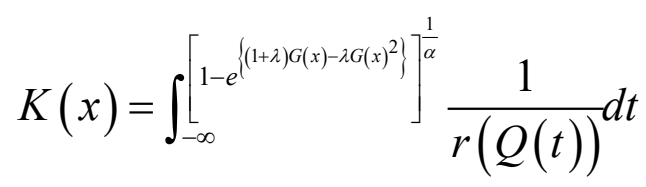

\section{Families of $q_{T}$ transmuted $X$ distributions of Type IV}

The CDF has the following integral representation for $\alpha>0$

$$
K(x)=\int_{-\infty}^{\left[\frac{e\left\{(1+\lambda) G(x)-\lambda G(x)^{2}\right\}}{1+e\left\{(1+\lambda) G(x)-\lambda G(x)^{2}\right\}}\right]^{\frac{1}{\alpha}}} \frac{1}{r(Q(t))} d t
$$

\section{Concluding Remarks}

Our hope is that researchers will find these class of distributions practically significant in modeling biological data, health data, etc. We hope the researchers will further develop the properties and applications of these new class of distributions.

\section{References}

1. Jayakumar K, Girish Babu M (2017) T-Transmuted X Family of Distributions. Statistica 77: 3. 
2. Shaw W, Buckley I (2007) The alchemy of probability distributions: beyond Gram-Charlier expansions, and a skew-kurtotic-normal distribution from a rank transmutation map. Research report.

3. Faton Merovci, Ibrahim Elbatal (2014) Transmuted Weibull-geometric distribution and its applications, Scientia Magna 10(1): 68-82

4. Eugene N, Lee C, Famoye F (2002) The beta-normal distribution and its applications. Communications in Statistics-Theory and Methods 31(4) 497-512.

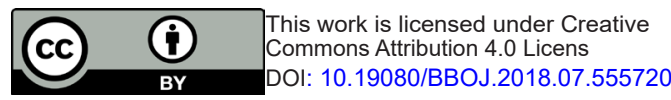

5. Alzaatreh A, Lee C, Famoye F (2013) A new method for generating families of continuous distributions. Metron 71(1): 63-79.

6. Clement Boateng Ampadu (2018) Quantile-generated family of distributions: a new method for generating continuous distributions. Fundamental Journal of Mathematics and Mathematical Sciences 9(1): $13-34$.

7. Muhammad S, Robert K, Irene Le (2016) Transmuted Gompertz Distribution: Properties and Estimation. Pak J Statist 32(3): 161-182.

\section{Your next submission with Juniper Publishers will reach you the below assets}

- Quality Editorial service

- Swift Peer Review

- Reprints availability

- E-prints Service

- Manuscript Podcast for convenient understanding

- Global attainment for your research

- Manuscript accessibility in different formats

( Pdf, E-pub, Full Text, Audio)

- Unceasing customer service

Track the below URL for one-step submission https://juniperpublishers.com/online-submission.php 